\title{
Enhanced occipital and anterior cingulate activation in men but not in women during exposure to angry and fearful male faces
}

\author{
HÅKAN FISCHER \\ Karolinska Institute, Stockholm, Sweden \\ PETER FRANSSON \\ Karolinska Hospital, Stockholm, Sweden \\ CHRISTOPHER I. WRIGHT \\ Massachusetts General Hospital, Brigham \& Women's Hospital, \\ and Harvard Medical School, Boston, Massachusetts \\ and \\ LARS BÄCKMAN \\ Karolinska Institute, Stockholm, Sweden
}

\begin{abstract}
Blood-oxygenation-level-dependent signal was measured with functional magnetic resonance imaging in 24 healthy young subjects ( 12 men and 12 women) during viewing of angry, fearful, and neutral male and female face pictures. Exposure to angry male as opposed to angry female faces activated the visual cortex and the anterior cingulate gyrus significantly more in men than in women. A similar sex-differential brain activation pattern was present during exposure to fearful but not neutral faces. Previous behavioral studies indicate enhanced physiological arousal in men but not in women during exposure to angry male as opposed to female faces, and brain imaging studies have shown that the occipital cortex and the anterior cingulate gyrus are influenced by activity in the autonomic nervous system as well as by visual attention. Hence, we suggest that the elevated occipital and anterior cingulate activation in men during confrontation with other angry and fearful males may reflect enhanced vigilance in a potentially dangerous situation.
\end{abstract}

The display of emotion is a critical factor in social interaction. With regard to the biological underpinnings of emotion, several brain-imaging studies have investigated neural activation during exposure to negative facial expressions (see Davis \& Whalen, 2001, for a review). However, other factors besides expressions provide critical cues in face-to-face interaction. From an evolutionary perspective, as well as from a sociocultural learning perspective, it is important to recognize not only the facial expression but also the identity of the displaying person. One important factor in this context is the sex of the interacting person. Evidence suggests that pictures of males expressing anger tend to be more effective as conditioned stimuli than pictures of angry females (Öhman \& Dimberg, 1978). These results were extended in a study that investigated the effect of the sex of both the receiver and the sender on

This research was supported by grants from the Sasakawa Young Leaders' Fellowship Fund, Faculty of Humanities and Social Sciences, Uppsala University (H.F.), and the Swedish Research Council (H.F. and L.B.). We thank Johan Sandblom and the staff at the Karolinska Hospital MR center for providing excellent data collection conditions. Correspondence should be addressed to H. Fischer, Aging Research Center, Karolinska Institute, Box 6401, 11382 Stockholm, Sweden (e-mail: hakan.fischer@neurotec.ki.se). aversive conditioning (Mazurski, Bond, Siddle, \& Lovibond, 1996). In that study, the investigators tested the hypothesis that men are more biologically prepared to react to angry male faces than to angry female faces, whereas women react similarly to both sexes. This hypothesis is based on evolutionary theories about dominance hierarchies, where dominance is intimately related to betweenindividual competition within the group (e.g., Hinde, 1974; Öhman, Dimberg, \& Öst, 1985).

To establish dominance, the competing individuals typically use impressive facial displays to threaten and frighten the opponent. On the basis of data from studies of nonhuman primates, Öhman et al. (1985) suggested that both men and women form hierarchies, with the male hierarchy dominating over the female. The conditioning data of Mazurski et al. (1996) supported this hypothesis in that only males showed a larger conditioned skin conductance response (SCR) to angry male faces as opposed to angry female faces. These data indicate that men may be more physiologically aroused during confrontation with other angry males than with angry females, an autonomic nervous system pattern not seen in women.

Recent brain-imaging studies including men and women have shown that angry faces, irrespective of the sex of sender, may activate regions in the left and right amygdala 
(Wright, Martis, Shin, Fischer, \& Rauch, 2002), the left and right parahippocampal gyri (Whalen et al., 2001), and the anterior (Blair, Morris, Frith, Perrett, \& Dolan, 1999) and posterior cingulate (Sprengelmeyer, Rausch, Eysel, \& Przuntek, 1998), as well as the orbitofrontal (Blair et al., 1999), temporal (Blair et al., 1999), prefrontal, and parietal cortices (Kilts, Egan, Gideon, Ely, \& Hoffman, 2003). To our knowledge, past research has not examined how the sex of the angry sender affects how male and female brains process this socially relevant information. Therefore, the aim of the present functional magnetic resonance imaging (fMRI) study was to investigate brain activation in men as opposed to women for angry male faces relative to angry female faces. On the basis of evolutionary theory (Öhman et al., 1985) and psychophysiological data (Mazurski et al., 1996), we hypothesized that men activate emotionally relevant brain regions during exposure to other angry male faces more than during exposure to angry female faces, a pattern of brain activation not seen to the same extent in women.

To examine the specificity of this brain activation pattern, we used areas activated in the target contrast (i.e., angry male vs. angry female faces in men vs. women) as regions of interest (ROIs) in two control contrasts (i.e., fearful male vs. fearful female faces and neutral male vs. neutral female faces in men as opposed to women). Bloodoxygenation-level-dependent (BOLD) signal was measured in young men and women during exposure to epochs of emotional and neutral male and female faces (Ekman \& Friesen, 1976). The study design is similar to one previously used by Whalen et al. (2001), with the important exception that we here presented male and female faces in separate blocks. With this design, it is possible to study how the interaction between the sex of the sender and that of the receiver influences activity in neural systems involved in emotional processing and in detection of socially relevant information in another person's face.

\section{METHOD}

\section{Subjects}

Twenty-four healthy right-handed subjects (12 male, 12 female) with a mean $( \pm S D)$ age of 25.0 years $( \pm 2.1)$ and 24.4 years $( \pm 3.4)$, respectively, were included. Persons with previous or current psychiatric, neurological, or medical disease, and persons who used psychoactive medication or abused substances were excluded. Pregnancy was also an exclusionary criterion. Written informed consent was obtained. The study was approved and conducted in accordance with guidelines established by the local ethical committee at the Karolinska Hospital.

\section{Procedure}

Subjects were positioned supine on a padded scanner bed in a dimly illuminated room and wore foam earplugs as well as external ear protection to attenuate scanner noise. During fMRI data acquisition, all subjects passively viewed pictures of male and female faces (Ekman \& Friesen, 1976) during a single 6-min run. This run was composed of fifteen 24 -sec epochs with male or female angry (A), fearful $(\mathrm{F})$, or neutral $(\mathrm{N})$ face stimuli, or a single cross on an otherwise blank screen that served as a low-level fixation condition (+). During each face epoch, subjects viewed 48 A, 48 F, or $48 \mathrm{~N}$ face stimuli (i.e., total of 8 presentations of each male or female face). Each face stimulus was presented for $200 \mathrm{msec}$ with an interstimulus interval of $300 \mathrm{msec}$ (Breiter et al., 1996; Whalen et al., 2001). The low-level fixation condition $(+)$ served as the first, middle, and last epochs in the run. Presentations of alternating A and F male and female face epochs were bracketed by epochs of $\mathrm{N}$ male and female faces. The order of male and female $\mathrm{A}$ and $\mathrm{F}$ epochs was counterbalanced across subjects (i.e., each of the four epoch orders described below was presented to 3 subjects of each sex in a randomized fashion). The epoch orders were as follows:

\section{1. +NmaleFmaleAmaleFmaleAmaleNmale +NfemaleAfemale}

FfemaleAfemaleFfemaleNfemale + .

2. + NfemaleFfemaleAfemaleFfemaleAfemaleNfemale + Nmale AmaleFmaleAmaleFmaleNmale + .

3. +NmaleAmaleFmaleAmaleFmaleNmale + NfemaleFfemale Afemale FfemaleAfemaleNfemale + .

4. +NfemaleAfemaleFfemaleAfemaleFfemaleNfemale +Nmale FmaleAmaleFmaleAmaleNmale +

Within each epoch, the faces were repeatedly presented in semirandom order both within and between subjects. Specifically, the pictures were presented in a counterbalanced order, with the exception that the same face never appeared twice in consecutive order. Before scanning, subjects were instructed to lie quietly and fixate the presented faces at the level of the eyes (i.e., passive viewing). After the experiment, subjects rated the emotionality of the presented faces to validate the degree of emotional significance of each face. None of the participating subjects admitted having seen the experimental faces prior to the experiment.

\section{Subjective Ratings}

A sample of the participating men $(n=9)$ and women $(n=10)$ rated the degree of anger in each of the depicted angry and neutral male and female faces, and the degree of fear in each of the depicted fearful and neutral male and female faces (range 0-100; 0: none, 100: maximum). Paired $t$ tests were used to test for differences in subjective ratings.

\section{Face Stimuli and Apparatus}

Face stimuli consisted of bitmap picture files displaying six male and six female individuals showing emotional and neutral facial expressions (Ekman \& Friesen, 1976). These picture files were presented by means of a standardized software (ERTS; Berisoft Corp, Germany) using an IBM Thinkpad 390 computer (IBM, USA) and projected via a Philips Hopper HG 20 Impact LCD projector (Philips Corp, Netherlands) positioned inside the scanner room onto a rectangular screen, placed approximately $3 \mathrm{~m}$ in front of the subject. Stimuli were presented via a mirror system (prism and oculars) mounted on top of the headcoil positioned approximately $2 \mathrm{~cm}$ from of the subject's eyes.

\section{Functional Magnetic Resonance Imaging}

Data acquisition. Whole-brain imaging data were acquired on a 1.5-T GE Signa Echospeed MR scanner (GE Medical Systems), using a standard circular head coil. T1-weighted 3-D-SPGR images $\left(\mathrm{TR}=24 \mathrm{msec}, \mathrm{TE}=6 \mathrm{msec}\right.$, flip angel $\left.=35^{\circ}\right)$ were acquired for anatomical coregistration in 124 contiguous 1.5 -mm coronal slices (image resolution $=256 \times 256 \times 186 \mathrm{~mm}$, voxel size $=0.9 \times 0.9$ $\times 1.5 \mathrm{~mm}$ ). Functional images were acquired using a T2*-sensitive gradient echo-EPI sequence $(\mathrm{TR}=4.2 \mathrm{sec}, \mathrm{TE}=40 \mathrm{msec}$, flip angle $=90^{\circ}$ ). The image volumes had an FOV of $220 \times 220 \mathrm{~mm}$, an in-plane resolution of $3.44 \times 3.44 \mathrm{~mm}^{2}$, and contained 42 horizontal 4-mm thick slices with a $0.4-\mathrm{mm}$ gap in between each slice. All images were acquired sequentially. During the fMRI session, 86 image volumes were obtained. To account for magnetic saturation effects, three dummy scans presented at the beginning of the session were discarded in the statistical analysis. 
Data analysis. Functional images were first realigned and unwarped (pitch and roll) to account for potential movement by field inhomogeneity effects (Andersson, Hutton, Ashburner, Turner, \& Friston, 2001), then motion corrected and normalized to a standard template using SPM2 (http://www.fil.ion.ucl.ac.uk/spm). Normalized images were spatially smoothed with a Gaussian filter of $12 \mathrm{~mm}$ full width at half maximum (FWHM). High- and low-frequency noise and differences in global signal between subjects were removed using a high-pass filter, a low-pass filter (Gaussian), and global scaling, respectively. Individual data were analyzed with a fixed-effects model (Friston, Jezzard, \& Turner, 1994), and group data were analyzed using a random-effects model (Holmes \& Friston, 1998). Effects were modeled using a boxcar convolved with a canonical hemodynamic response function. For the group analysis, functional images from the different conditions were contrasted to create a single contrast image per subject and contrast. Maxima of clusters of activated voxels are reported in Talairach coordinates (Talairach \& Tournoux, 1988). The mni2tal.m matlab function (www. mrc-cbu.cam.ac.uk/Imaging/mnispace.html) was used to transform MNI coordinates (Montreal Neurological Institute) to Talairach coordinates (Talairach \& Tournoux, 1988).

To identify brain areas in men and women that were more activated by (1) angry versus neutral faces collapsed over sex of face, and (2) angry male versus angry female faces, one-sample $t$ tests were performed on individual contrast images. To identify brain areas in men that were more activated than corresponding areas in women by angry, fearful, and neutral male versus angry, fearful, and neutral female faces, we conducted two-sample $t$-tests on the individual contrast images in men as opposed to women. Because a large number of studies have demonstrated involvement of the amygdala in perception of negative affective faces (e.g., Breiter et al., 1996; Morris et al., 1998; Morris et al., 1996; Phillips et al., 1998; Phillips et al., 1997; Whalen et al., 1998; Whalen et al., 2001), $p$ values for activations in the amygdala were corrected for the brain volume analyzed (specified as a sphere with a radius of $8 \mathrm{~mm}$; Worsley, Marrett, Neelin, Friston, \& Evens, 1996). In this predefined area of interest, we used a voxel-level threshold of $p<.05$, corrected for the volume of interest. Additional a priori regions of interest were other areas previously shown to activate during emotional processing (see Phan, Wager, Taylor, \& Liberzon, 2002, for a review). These regions included subcortical regions such as the hippocampus and the hypothalamus, as well as cortical regions in both the anterior and posterior brain, including the occipital and the anterior cingulate cortices (ACC). For this extended network of brain areas, we used a voxel-level threshold of $p<.001$, uncorrected for search volume. For the rest of the brain, we used a voxel-level threshold of $p<.05$, corrected for search volume. To test the origin of the interaction between type of face (angry or fearful male faces vs. angry or fearful female faces) and sex group (men vs. women), analysis of variance
(ANOVA) and follow-up paired (within groups) or unpaired (between groups) $t$ tests were conducted using $\beta$ values (i.e., parameter effect sizes). These $\beta$ values reflect BOLD activation (task vs. baseline) in the maximum voxel location in the activated clusters of voxels reported in Table 1.

\section{RESULTS}

\section{Behavioral Ratings of Face Stimuli}

As expected, the angry faces $(M=55.0, S D=21.5)$ were perceived as angrier than the neutral faces $(M=$ $11.2, S D=11.2, p<.0001)$. Importantly, angry male and female faces were rated as expressing the same degree of anger by both sexes (for men: $M=56.5, S D=18.3$ and $M=54.4, S D=18.2$, respectively, $p>.30$; for women: $M=55.1, S D=24.8$ and $M=54.1, S D=26.0$, respectively, $p>.65$ ). Men and women also rated neutral male faces and female faces as being equally expressive in terms of anger (for men: $M=11.8, S D=9.6$ and $M=$ $10.0, S D=10.5$, respectively, $p>.25$; for women: $M=$ $12.5, S D=14.2$ and $M=10.5, S D=12.0$, respectively, $p>.15)$.

Also, the fearful faces $(M=65.9, S D=16.1)$ were perceived as being more emotional (i.e., fearful) than the neutral faces $(M=5.1, S D=6.6, p<.0001)$. Furthermore, both men and women rated fearful male and fearful female faces as expressing a similar degree of fear (for men: $M=$ 70.3, $S D=12.9$ and $M=64.7, S D=12.5$, respectively, $p>.10$; for women: $M=66.0, S D=21.0$ and $M=62.1$, $S D=18.7$, respectively, $p>.05$ ). Finally, both sexes rated neutral male faces and female faces as being equally expressive in terms of fear (for men: $M=3.3, S D=3.7$ and $M=3.9, S D=7.1$, respectively, $p>.25$; for women: $M=$ $5.8, S D=7.9$ and $M=7.2, S D=8.6$, respectively, $p>.50$ ).

\section{fMRI Data}

Greater activation to angry versus neutral faces in men and women. Men and women activated the right amygdala during exposure to angry as opposed to neutral faces collapsed over sex of face (cluster size $=55$ voxels; $t=2.81$ in peak voxel activation, Talairach coordinates; $x=20, y=-6, z=20, p<.005$, using small-volume correction).

Table 1

Brain Regions More Activated in Men Than in Women During Exposure to Angry Male as Opposed to Angry Female Faces

\begin{tabular}{lccccccc}
\hline Brain Region & Hemisphere & Brodmann Area & $x$ & $y$ & $z$ & Cluster Size & $t$ Value \\
\hline Occipital cortex & $\mathrm{R}$ & $\underline{17} / 18$ & 19 & -78 & 09 & 128 & 4.42 \\
& & $17 / \underline{18}$ & 12 & -81 & 17 & & 4.14 \\
Cingulate cortex & $\mathrm{R}$ & $24 \underline{\underline{32}}$ & 14 & 32 & 20 & 83 & 4.30 \\
Cingulate cortex & $\mathrm{L}$ & 32 & -02 & 46 & -01 & 22 & 3.76 \\
\hline
\end{tabular}

Note-Spatial coordinates are for peak voxel activation or activations in a cluster of suprathreshold voxels $(p<.001$, uncorrected) that covers one or several brain regions and Brodmann areas. Coordinates are in millimeters and correspond to the stereotactic atlas of Talairach and Tournoux (1988). An underlined Brodmann area reflects the approximated localization of the maximum voxel in a voxel cluster that extends over more than one Brodmann area. For the $x$ coordinate (right-left), negative values are in the left hemisphere, whereas negative values related to the $y$ coordinate (anterior-posterior) are posterior to the zero point (located at the anterior commisure). For the $z$ coordinate (superior-inferior), negative values are inferior to the plane defined by the anterior and posterior commisure. The $t$ values correspond to the peak voxel activation. R means right and $\mathrm{L}$ means left. 
Greater activation to angry male versus angry female faces in men and women. There were no brain regions that showed significant activation for angry male as opposed to angry female faces that generalized across sex.

Greater activation to angry male versus angry female faces in men as opposed to women. Men activated early visual areas in the right hemisphere more than women during exposure to angry male faces as opposed to angry female faces (Table 1, Figure 1). An ANOVA revealed a significant interaction between type of face (angry male faces vs. angry female faces) and sex (men vs. women) $[F(1,22)=18.20, p<.001 ;$ Figure 1$]$.

Follow-up tests showed greater activation in men to angry male faces $(M=.74, S D=.74)$ than to angry female faces $(M=-.20, S D=.28 ; t=4.13, p<.01)$, whereas women showed similar activation to angry male $(M=.01, S D=.62)$ and angry female $(M=.49, S D=$ $.54 ; t=1.99, p>.05)$ faces. Men $(M=.74, S D=.74)$
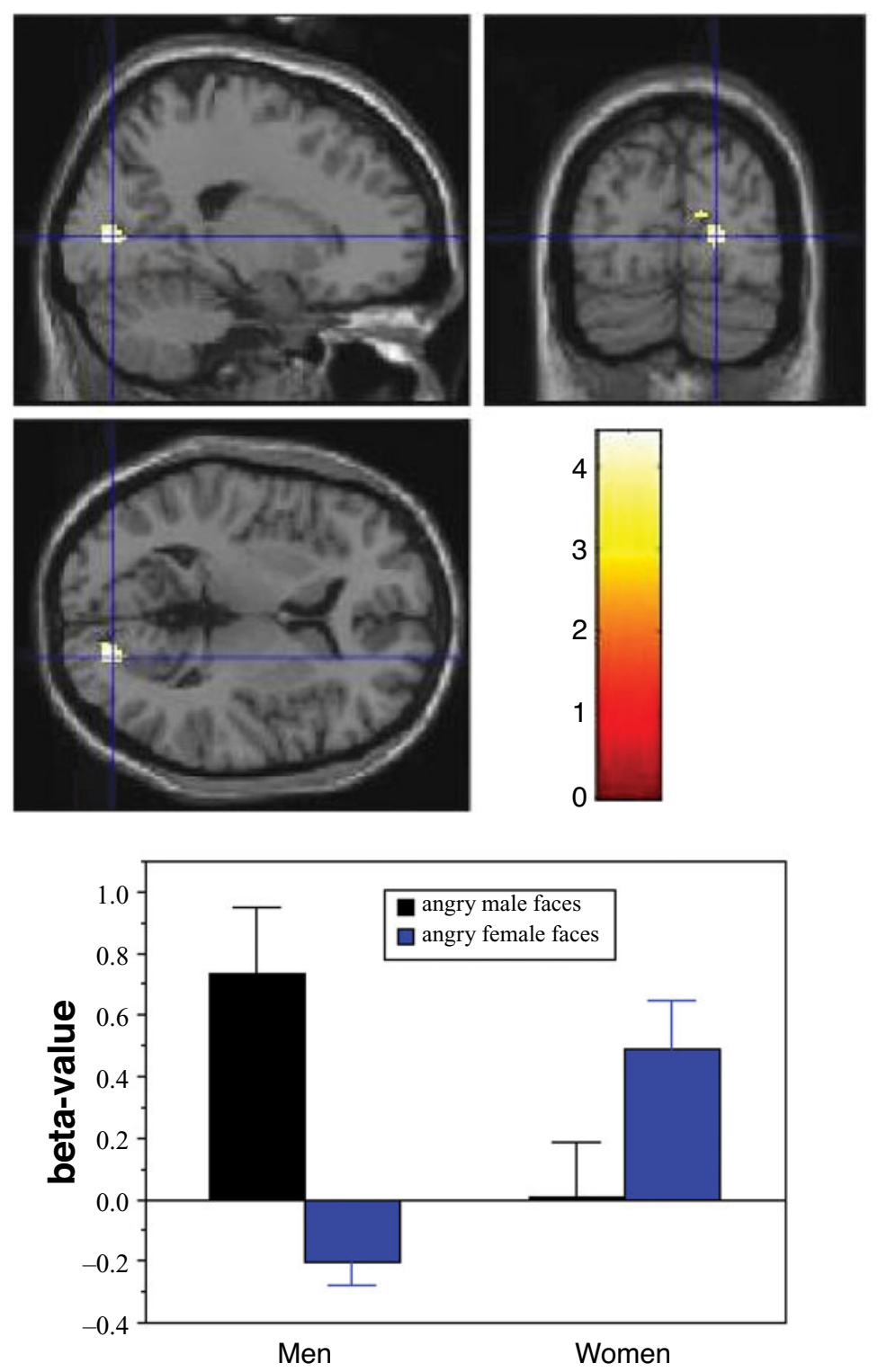

Figure 1. Higher right-sided occipital cortex activation in men as opposed to women during exposure to angry male versus angry female faces. The colored statistical $t$ map is superimposed on the T1 template in SPM2. Local maximum in the occipital cortex is located in the center of the blue cross. The graph displays $\beta$ values $(M$ and $S E$ ) derived from this local maximum for angry male and angry female faces in men and women. 
showed greater activation than women $(M=.01, S D=$ $.62)$ to angry male faces $(t=2.60, p<.05)$, whereas women $(M=.49, S D=.54)$ showed greater activation than men $(M=-.20, S D=.28)$ to angry female faces $(t=3.89, p<.0001)$.

Men also activated two subregions of the ACC more than women during exposure to angry male faces relative to angry female faces (Table 1; Figures 2 and 3). There were significant interactions between type of face and sex both in the more right-sided dorsal part of the ACC $[F(1,22)=17.08, p<.001]$ and in the more left-sided rostral-ventral part of the ACC $[F(1,22)=14.01, p<.01]$.

Follow-up tests in the right dorsal ACC also showed greater activation in men to angry male faces $(M=-.01$, $S D=.45)$ than to angry female faces $(M=-.69, S D=$ $.57 ; t=3.78, p<.01)$, whereas women showed similar activation to angry male $(M=-.84, S D=.82)$ and angry female faces $(M=-.12, S D=.51 ; t=-2.19, p>.05)$.
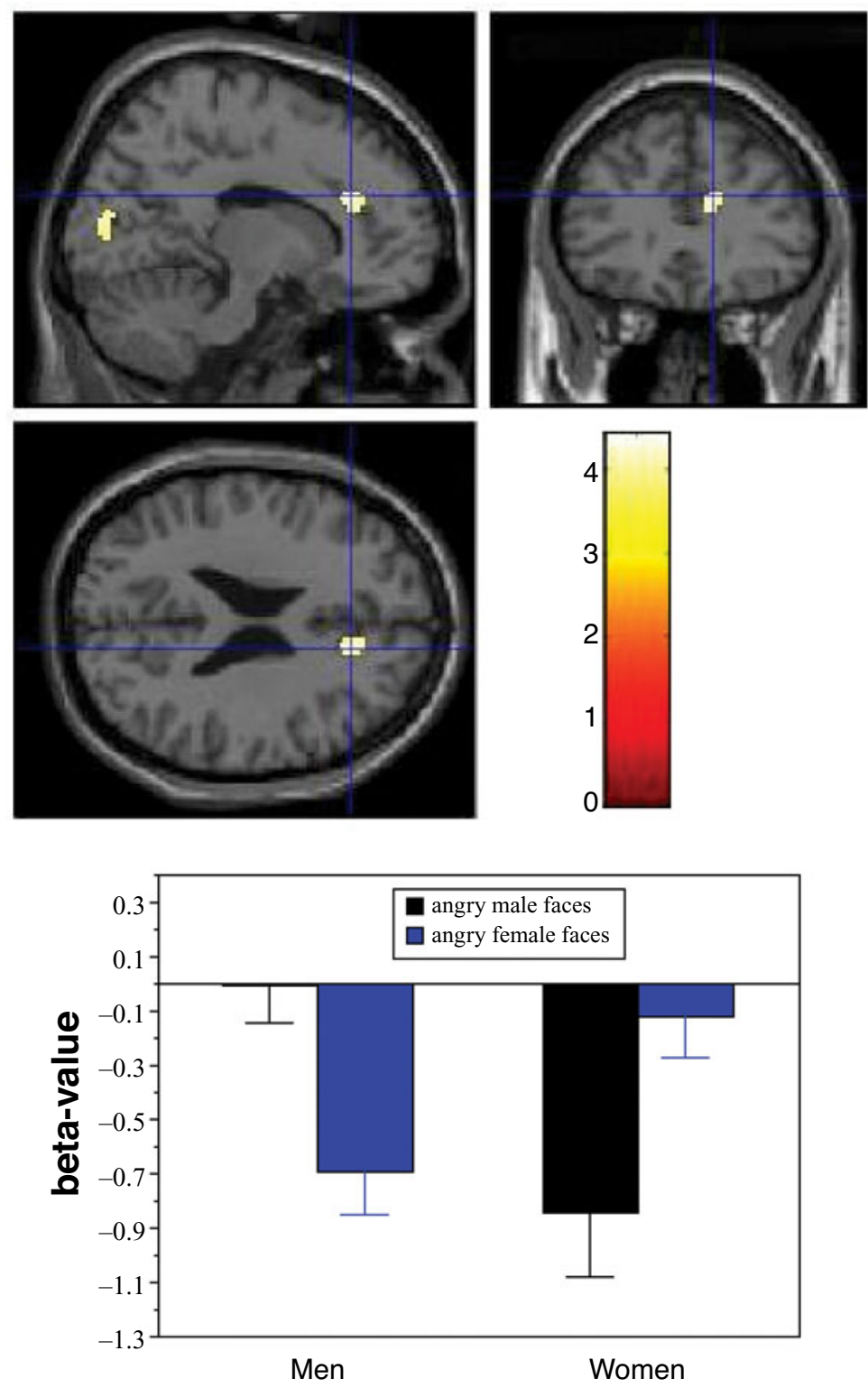

Figure 2. Higher right-sided dorsal anterior cingulate cortex activation in men as opposed to women during exposure to angry male versus angry female faces. The colored statistical $t$ map is superimposed on the T1 template in SPM2. Local maximum in the dorsal anterior cingulate cortex is located in the center of the blue cross. The graph displays $\beta$ values $(M$ and $S E$ ) derived from this local maximum for angry male and angry female faces in men and women. 

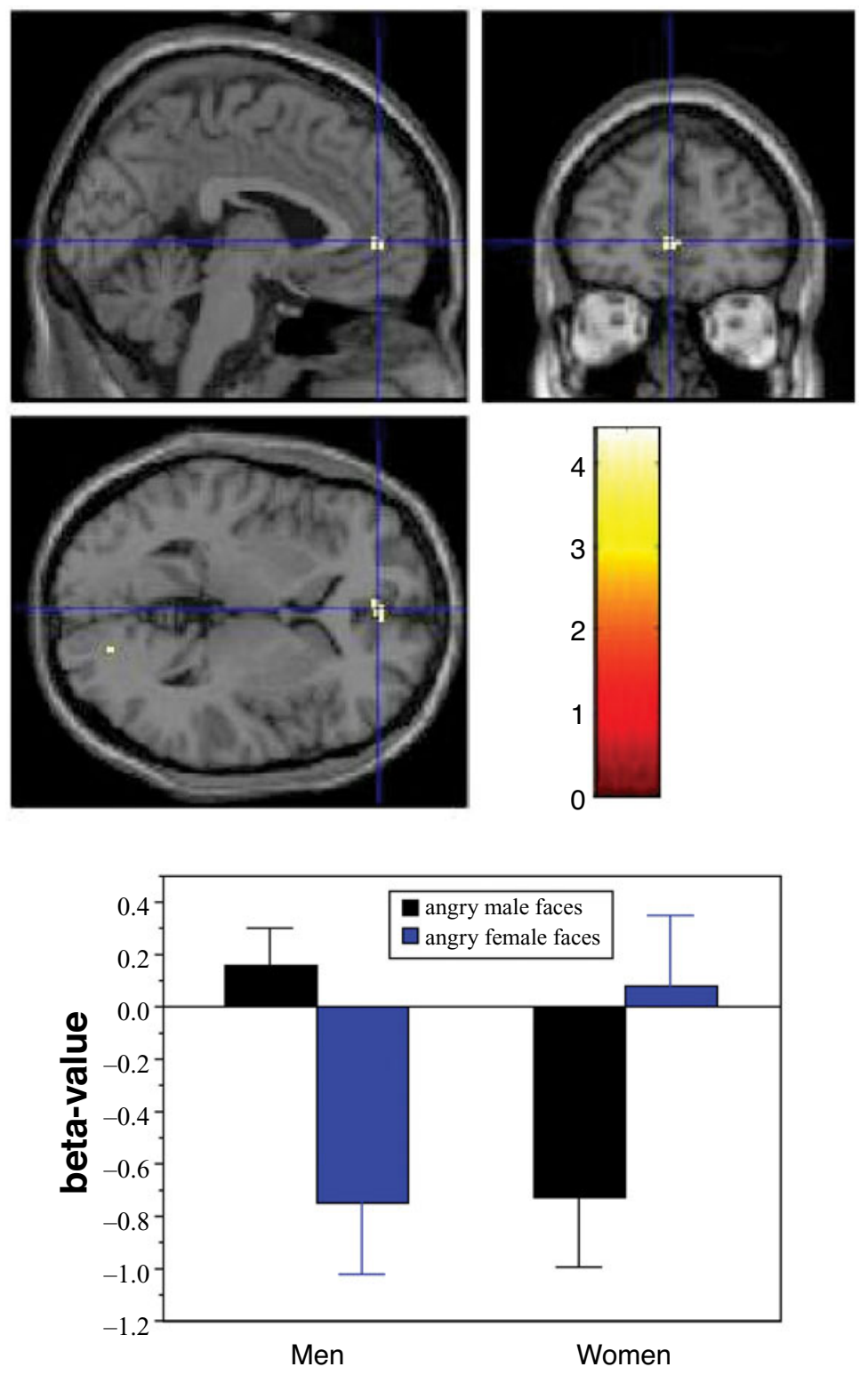

Figure 3. Higher left-sided rostral-ventral anterior cingulate cortex activation in men as opposed to women during exposure to angry male versus angry female faces. The colored statistical $t$ map is superimposed on the T1 template in SPM2. Local maximum in the rostral-ventral anterior cingulate cortex is located in the center of the blue cross. The graph displays $\beta$ values ( $M$ and $S E$ ) derived from this local maximum for angry male and angry female faces in men and women.

Men $(M=-.01, S D=.45)$ showed higher activation than women $(M=-.84, S D=.82)$ to angry male faces $(t=$ $3.11, p<.01)$, whereas women $(M=-.12, S D=.51)$ showed higher activation than $\operatorname{men}(M=-.69, S D=.57)$ to angry female faces $(t=2.58, p<.05)$.

Similar follow-up tests in the left rostral-ventral ACC showed significantly higher activation in men to angry male faces $(M=.16, S D=.47)$ than to angry female faces $(M=-.75, S D=.92 ; t=3.1, p<.01)$. However, women also showed higher activation to angry faces of the same $(M=.08, S D=.92)$ versus the opposite sex $(M=$ $-.73, S D=.90 ; t=2.22, p<.05)$. Men $(M=.16, S D=$ $.47)$ demonstrated higher activation than women $(M=$ $-.73, S D=.90)$ to angry male faces $(t=3.03, p<.01)$, 
whereas women $(M=.08, S D=.92)$ demonstrated higher activation than men $(M=-.75, S D=.92)$ to angry female faces $(t=2.21, p<.05)$.

Greater activation in predefined ROIs to fearful male versus fearful female faces in men as opposed to women. The same brain regions were activated in the fearful male versus fearful female faces contrast as in the angry male versus angry female faces contrast in men as opposed to women (see Table 1). ANOVAs showed that these regional differences reflected a significant interaction between type of face (fearful male faces vs. fearful female faces) and sex group (men vs. women) in the occipital cortex $[F(1,22)=15.11, p<.001]$ as well as in the more right-sided dorsal $[F(1,22)=18.69, p<.001]$ and the more left-sided rostral-ventral part of the ACC $[F(1,22)=5.98, p<.05]$.

Follow-up tests showed that the interaction between type of face and sex in the occipital cortex reflected greater activation in men to fearful male faces $(M=.72, S D=$ .77) than to fearful female faces $(M=-.26, S D=.36$; $t=4.03, p<.01)$. Women, on the other hand, showed similar activation to fearful female faces $(M=.37, S D=$ $.60)$ and fearful male faces $(M=.02, S D=.50 ; t=1.47$, $p>.10)$. Moreover, men activated the occipital cortex more than women during exposure to fearful male faces $(M=.72, S D=.77$ for men and $M=.02, S D=.50$ for women; $t=2.62, p<.05$ ). Women activated the same region more than men during exposure to fearful female faces $(M=.37, S D=.60$ for women and $M=-.26$, $S D=.36$ for men; $t=3.11, p<.01)$.

Also, in the dorsal ACC, there was greater activation in men to fearful male faces $(M=.12, S D=.52)$ than to fearful female faces $(M=-.80, S D=.58 ; t=4.77, p<$ $.001)$, whereas women demonstrated similar activation to fearful faces of both sexes $(M=-.73, S D=.70$ for fearful male faces and $M=-.08, S D=.58$ for fearful female faces; $t=-2.11, p>.05$ ). Furthermore, both men and women activated the dorsal ACC more during exposure to fearful faces of their own sex $(M=.12, S D=.52$ for men and $M=-.08, S D=.58$ for women) as opposed to fearful faces of the opposite $\operatorname{sex}(M=-.80, S D=.58$ for men and $M=-.73, S D=.70$ for women; $t=3.39, p<.01$ and $t=3.03, p<.01$, for men and women, respectively).

In the rostral-ventral ACC, as in the other ROIs, followup tests demonstrated greater activation in men to fearful male faces $(M=.14, S D=.58)$ than to fearful female faces $(M=-.76, S D=.84 ; t=2.75, p<.05)$, but no significant difference in women during exposure to fearful male faces $(M=-.18, S D=.77)$ and fearful female faces $(M=.19, S D=.91 ; t=-.91, p>.30)$. Finally, there was similar activation in men and women during exposure to fearful male faces $(M=-.14, S D=.58$ for men and $M=-.18, S D=.77$ for women; $t=1.14, p<.30$ ), but higher activation in women than men to fearful female faces $(M=.19, S D=.91$ for women and $M=-.76$, $S D=.84$ for men; $t=2.65, p<.05)$.
Greater activation in predefined ROIs to neutral male versus neutral female faces in men as opposed to women. No fMRI signal difference was evident in the neutral male faces versus neutral female faces contrast in the ROIs defined by the angry male versus angry female faces contrast.

\section{DISCUSSION}

In agreement with the bulk of evidence, men and women alike exhibited greater amygdala activity during exposure to angry as opposed to neutral faces (Whalen et al., 2001; Wright et al., 2002). However, the chief interest of the present study was to examine potential sex-differential brain activation patterns as a function of sex of face and emotional expression. The relevant results showed that men, as opposed to women, activated brain areas in the occipital and the anterior cingulate cortices more during confrontation with angry male faces than with angry female faces. Of note is that no other region of interest showed sex-differential activation, despite the fact that we used the same statistical threshold for a number of additional and extended brain regions (Phan et al., 2002). Thus, to the extent that men are more biologically prepared than women to react emotionally when confronting angry males, as both evolutionary theory (Öhman et al., 1985) and psychophysiological data (Mazurski et al., 1996) suggest, the neural correlate of this sex difference appears to reside within early visual processing areas, as well as in the ACC. Interestingly, the same brain regions were also more activated in men than in women during confrontation with fearful male faces as opposed to fearful female faces, a sex-differential brain activation pattern not present during exposure to neutral faces. These results suggest that men and women may differ in their neural processing during face-to-face exposure to other males as opposed to other females, but only if the sender is expressing negative facial affect. Whether this similarity in brain activation patterns for angry and fearful faces reflects similar underlying neural processes remains for future research to determine.

An important question concerns whether these brain activation patterns reflect nature, nurture, or both. Although the origin of the sex-differential neural networks could reside in our genetic makeup, they might also reflect social-cultural learning or a combination of these factors. On the basis of the current data, it is not possible to disentangle these possibilities.

As noted, Mazurski et al. (1996) demonstrated that men were more physiologically aroused than women when confronting angry male faces than when confronting angry female faces. The present signal enhancement in early visual processing areas and in the ACC in men during exposure to, at least, angry male faces, probably reflects this peripheral arousal enhancement. That activation in early visual areas in men to other angry male faces could 
be associated with autonomic nervous system arousal is supported by findings from other brain-imaging studies in which both the visual cortex and the autonomic nervous system were engaged during exposure to different biologically relevant visual stimuli. For example, studies with healthy subjects (Fischer, Wik, \& Fredrikson, 1996; Lane et al., 1997; Lang et al., 1998; Reiman et al., 1997) as well as simple phobics (Fredrikson, Wik, Annas, Ericson, \& Stone-Elander, 1995; Wik et al., 1993) indicate parallel enhancement of activity in the visual cortex and the autonomic nervous system during viewing of negative affectladen visual stimuli. Notably, these occipital activations are usually more extended than those observed in the present study. A more direct relation between electrodermal and occipital activation has been shown using different functional brain-imaging paradigms. Critchley, Elliott, Mathias, and Dolan (2000) demonstrated a relationship between skin conductance responses (SCR) and activity in the visual cortex in a gambling task, and Williams et al. (2000) found an association between SCR and occipital brain activity during passive viewing of checkerboard patterns. Moreover, Patterson, Ungerleider, and Bandettini (2002) showed that SCR and activity in occipital regions were related in a variety of tasks. Both Williams et al. (2000) and Patterson et al. suggested that attentional modulation is a critical factor for this general visual activation across different tasks. Hence, activation of brain systems involved in both peripheral physiological arousal and visual attention may explain why early visual areas are more engaged when men view angry male faces as opposed to angry female faces.

Two clusters of voxels in the ACC were activated in the same contrast, one in the rostral-ventral and one in the more dorsal part of this brain region. Both lesion and functionalimaging studies indicate separate roles for these areas in emotional and cognitive processing, respectively (Bush, Luu, \& Posner, 2000). The more rostral-ventral subdivision of the ACC has its strongest connections to limbic and paralimbic brain regions such as the amygdala and the orbitofrontal cortex (Devinsky, Morrell, \& Vogt, 1995) and is, accordingly, involved in the regulation of autonomic nervous system activity. This so-called affective division of the ACC is primarily involved in assessing the salience of emotional stimuli and in regulating emotional responses (Bush et al., 2000). The more dorsal "cognitive" subdivision of the ACC (Bush et al., 2000) is part of a distributed cortical network including lateral prefrontal, parietal, premotor, and supplementary motor areas (Devinsky et al., 1995). This network is involved in attentional modulation by influencing sensory processing and response selection (Bush et al., 1998; Vogt, Finch, \& Olson, 1992). We hypothesize that the activation of the emotional subdivision of the ACC in men, during exposure to other angry male faces, is associated with activation of the autonomic nervous system. Further, the parallel activation of the dorsal subdivision may indicate enhanced attention in men during exposure to angry male faces. Hence, the present activation patterns may reflect central neural correlates of a defense response in men during confrontation with potentially dangerous angry males, and possibly also to males whose fearful faces signal potential danger.

A limitation of the present study is that no fMRI BOLD signal was collected in the inferior medial prefrontal region because of susceptibility artifacts. As selective neurons that convey information from faces important to the evaluation and utilization of reinforcement inputs in social situations are located here (Rolls, 1999), an important task for future research is to determine how this brain region is involved in the present study context. Another potential limitation is that all participating individuals had viewed a different set of fearful and neutral faces (Lundqvist, Flykt, \& Öhman, 1998) prior to the present investigation. However, because the primary aim of this investigation was to study the sex $\times$ expression interaction using angry faces (Ekman \& Friesen, 1976), preexposure to faces showing other expressions should not be problematic, at least not in areas outside the amygdala, the hippocampus, and the inferior temporal cortex (Fischer et al., 2003).

In conclusion, the present study demonstrates that the occipital cortex and the ACC are more activated in men than in women during exposure to angry male as opposed to angry female faces, a sex-differential brain activation pattern also seen during exposure to fearful faces. Hence, early visual regions as well as the ACC respond differentially to emotional faces depending on the sex of both the sender and the receiver. These results extend previous brain-imaging findings by showing that not only the facial expression (Davis \& Whalen, 2001) but also the sex of the sender and receiver is a critical factor that determines which brain regions are engaged during exposure to emotional faces.

\section{REFERENCES}

Andersson, J. L., Hutton, C., Ashburner, J., Turner, R., \& FrisTON, K. (2001). Modeling geometric deformations in EPI time series. NeuroImage, 13, 903-919.

Blair, R. J., Morris, J. S., Frith, C. D., Perrett, D. I., \& Dolan, R. (1999). Dissociable neural responses to facial expressions of sadness and anger. Brain, 122, 883-893.

Breiter, H. C., Etcoff, N. L., Whalen, P. J., Kennedy, W. A., Rauch, S. L., Buckner, R. L., Strauss, M. M., Hyman, S. E., \& Rosen, B. R. (1996). Response and habituation of the human amygdala during visual processing of facial expression. Neuron, 17, 875-887.

Bush, G., LuU, P., \& Posner, M. I. (2000). Cognitive and emotional influences in anterior cingulate cortex. Trends in Cognitive Sciences, $\underline{\mathbf{4}}$, 215-222.

Bush, G., Whalen, P. J., Rosen, B. R., Jenike, M. A., McInerney, S. C., \& RaUCH, S. L. (1998). The counting Stroop: An interference task specialized for functional neuroimaging-validation study with functional MRI. Human Brain Mapping, 6, 270-282.

Critchley, H. D., Elliott, R., Mathias, C. J., \& Dolan, R. J. (2000). Neural activity relating to generation and representation of galvanic skin conductance responses: A functional magnetic resonance imaging study. Journal of Neuroscience, 20, 3033-3040.

Davis, M., \& Whalen, P. J. (2001). The amygdala: Vigilance and emotion. Molecular Psychiatry, 6, 13-34.

DevinsKy, O., Morrell, M. J., \& Vogt, B. A. (1995). Contributions of anterior cingulate cortex to behaviour. Brain, 118, 279-306. 
Ekman, P., \& Friesen, W. V. (1976). Pictures of facial affect. Palo Alto, CA: Consulting Psychologists Press.

Fischer, H., WiK, G., \& Fredrikson, M. (1996). Functional neuroanatomy of robbery re-experience: Affective memories studied with PET. NeuroReport, 7, 2081-2086.

Fischer, H., Wright, C. I., Whalen, P. J., McInerney, S. C., Shin, L. M., \& RAUCH, S. L. (2003). Brain habituation during repeated exposure to fearful and neutral faces: A functional MRI study. Brain Research Bulletin, 59, 387-392.

FrEDRIKSON, M., WIK, G., ANNAS, P., ERICSON, K., \& STONE-Elander, S. (1995). Functional neuroanatomy of visually elicited simple phobic fear: Additional data and theoretical analysis. Psychophysiology, 32, 43-48.

Friston, K. J., Jezzard, P., \& Turner, R. (1994). Analysis of functional MRI time-series. Human Brain Mapping, 1, 153-171.

Hinde, R. A. (1974). Biological bases of human social behavior. New York: McGraw-Hill.

Holmes, A. P., \& Friston, K. J. (1998). Generalizability, random effects, and population inference [Abstract]. NeuroImage, 7, S754.

Kilts, C. D., Egan, G., Gideon, D. A., Ely, T. D., \& Hoffman, J. M. (2003). Dissociable neural pathways are involved in the recognition of emotion in static and dynamic facial expressions. NeuroImage, $\mathbf{1 8}$, 156-168.

Lane, R. D., Reiman, E. M., Bradley, M. M., Lang, P. J., Ahern, G. L., Davidson, R. J., \& Schwartz, G. E. (1997). Neuroanatomical correlates of pleasant and unpleasant emotion. Neuropsychologia, $\mathbf{3 5}$, $1437-1444$

Lang, P. J., Bradley, M. M., Fitzsimmons, J. R., Cuthbert, B. N., Scott, J. D., Moulder, B., \& Nangia, V. (1998). Emotional arousal and activation of the visual cortex: An $\mathrm{f}$ MRI analysis. Psychophysiology, 35, 199-210.

LUNDQVist, D., FlykT, A., \& ÖHman, A. (1998). The Karolinska Directed Emotional Faces-KDEF [CD ROM]. Stockholm: Karolinska Institutet, Department of Clinical Neuroscience, Psychology Section.

Mazurski, E. J., Bond, N. W., Siddle, D. A. T., \& Lovibond, P. F. (1996). Conditioning with facial expressions of emotion: Effects of CS sex and age. Psychophysiology, 33, 416-425.

Morris, J. S., Friston, K. J., BüChel, C., Frith, C. D., Young, A. W., CAlder, A. J., \& Dolan, R. J. (1998). A neuromodulatory role for the human amygdala in processing emotional facial expressions. Brain, 121, 47-57.

Morris, J. S., Frith, C. D., Perrett, D. I., Rowland, D., Young, A. W., Calder, A. J., \& Dolan, R. J. (1996). A differential response in the human amygdala to fearful and happy facial expressions. $\mathrm{Na}$ ture, $\mathbf{3 8 3}, 812-815$.

Öhman, A., \& Dimberg, U. (1978). Facial expressions as conditioned stimuli for electrodermal responses: A case of preparedness? Journal of Personality \& Social Psychology, 6, 1251-1258.

Öhman, A., Dimberg, U., \& Öst, L.-G. (1985). Animal and social phobics: Biological constraints on learned fear responses. In S. Reiss \& R. R. Bootzin (Eds.), Theoretical issues in behavioral therapy (pp. 123174). Orlando, FL: Academic Press.

Patterson, J. C., II, Ungerleider, L. G., \& Bandettini, P. A. (2002). Task-independent functional brain activity correlation with skin conductance changes: An fMRI study. NeuroImage, 17, 1797-1806.
Phan, K. L., Wager, T. [D.], Taylor, S. F., \& Liberzon, I. (2002). Functional neuroanatomy of emotion: A meta-analysis of emotion activation studies in PET and fMRI. NeuroImage, 16, 331-348.

Phillips, M. L., Young, A. W., Scott, S. K., Calder, A. J., ANDrew, C., Giampietro, V., Williams, S. C., Bullmore, E. T., Brammer, M., \& Gray, J. A. (1998). Neural responses to facial and vocal expressions of fear and disgust. Proceedings of the Royal Society of London: Series B, 265, 1809-1817.

Phillips, M. L., Young, A. W., Senior, C., Brammer, M., Andrew, C., Calder, A. J., Bullmore, E. T., Perrett, D. I., Rowland, D., Williams, S. C., Gray, J. A., \& David, A. S. (1997). A specific neural substrate for perceiving facial expressions of disgust. Nature, 389, 495-498.

Reiman, E. M., Lane, R. D., Ahern, G. L., Schwartz, G. E., Davidson, R. J., Friston, K. J., Yun, L. S., \& Chen, K. (1997). Neuroanatomical correlates of externally and internally generated human emotion. American Journal of Psychiatry, 154, 918-925.

Rolls, E. T. (1999). The brain and emotion (pp. 113-134). Oxford: Oxford University Press.

Sprengelmeyer, R., Rausch, M., Eysel, U. T., \& Przuntek, H. (1998). Neural structures associated with recognition of facial expressions of basic emotions. Proceedings of the Royal Society of London: Series B, 265, 1927-1931.

TAlairach, J., \& Tournoux, P. (1988). Co-planar stereotaxic atlas of the human brain. New York: Thieme.

Vogt, B. A., Finch, D. M., \& Olson, C. R. (1992). Functional heterogeneity in cingulate cortex: The anterior executive and posterior evaluative regions. Cerebral Cortex, 2, 435-443.

Whalen, P. J., Rauch, S. L., Etcoff, N. L., McInerney, S. C., Lee, M. B., \& JeNIKE, M. A. (1998). Masked presentations of emotional facial expressions modulate amygdala activity without explicit knowledge. Journal of Neuroscience, 18, 411-418.

Whalen, P. J., Shin, L. M., McInerney, S. C., Fischer, H., Wright, C. I., \& RAUCH, S. L. (2001). A functional MRI study of human amygdala responses to facial expressions of fear versus anger. Emotion, 1, 70-83.

Wik, G., Fredrikson, M., Ericson, K., Eriksson, L., Stone-Elander, S., \& Greitz, T. (1993). A functional cerebral response to frightening visual stimulation. Psychiatry Research: Neuroimaging, 50, 15-24.

Williams, L. M., Brammer, M. J., Skerrett, D., Lagopolous, J., Rennie, C., Kozek, K., Olivieri, G., Peduto, T., \& Gordon, E. (2000). The neural correlates of orienting: An integration of $f$ MRI and skin conductance orienting. NeuroReport, 11, 3011-3015.

Worsley, K. J., Marrett, P., Neelin, A. C., Friston, K. J., \& Evans, A. C. (1996). A unified statistical approach for determining significant signals in images of cerebral activation. Human Brain Mapping, 4, 58-73.

WRight C. I., Martis, B., Shin, L. M., Fischer, H., \& Rauch, S. L. (2002). Enhanced amygdala response to emotional versus neutral schematic facial expressions. NeuroReport, 13, 785-790.

(Manuscript received September 15, 2003;) revision accepted for publication June 7, 2004.) 